\title{
Tribological response of an epoxy matrix filled with graphite and/or carbon nanotubes
}

\author{
M. M. SAKKA ${ }^{1, *}$, Z. ANTAR ${ }^{1}$, K. ELLEUCH ${ }^{1}$, J. F. FELLER ${ }^{2}$ \\ ${ }^{1}$ Laboratoire de Génie des Matériaux et Environnement, ENIS, Université de Sfax, Sfax BP. 1173-3038, Tunisia \\ ${ }^{2}$ Smart Plastics Group, European University of Brittany (UEB), LIMATB-UBS, Lorient 56321, France \\ Received: 29 July 2016 / Revised: 19 October 2016 / Accepted: 21 December 2016 \\ (C) The author(s) 2017. This article is published with open access at Springerlink.com
}

\begin{abstract}
Reinforced polymer-matrix composites are widely used under sliding contact conditions in various boating and automotive applications. In this paper, the friction and wear of bulk epoxy and carbon filler reinforced epoxy composites have been investigated using a pin-on-disc tribometer. The effect of different fillers on the tribological behavior of an epoxy has been studied using treated and untreated carbon nanotubes, graphite, and a mixture of graphite and carbon nanotubes. Filler addition greatly enhances the tribological properties of the epoxy resin, by reducing the friction coefficient and the wear rate. In addition, it was found that the treated carbon nanotubes/epoxy composites have the best tribological behavior. Moreover, a correlation between contact temperature and friction coefficient is reported. Finally, the wear mechanisms were determined by scanning electronic microscopy.
\end{abstract}

Keywords: epoxy composites; carbon nanotubes; wear; friction temperature

\section{Introduction}

Polymers play a very important part in mechanical and materials engineering, not just because they are easy to manufacture and their per unit cost is low, but also for their excellent tribological performance in engineered forms [1]. In the bulk or pristine form, only a few polymers would satisfy most of the tribological requirements; however, in their hybrid and composite forms, polymers often have the advantage of low weight and corrosion resistant over other materials such as metals and ceramics [1]. Tribological applications of polymers include gears [2], a range of bearings [3], artificial human joint bearing surfaces [4], bearing materials for space applications [5], tires, shoe soles, automobile brake pads, non-stick frying pans, floorings, and various types of surfaces for optimum tactile properties, such as fibers [6]. Similar to the bulk mechanical responses, tribological characteristics of polymers are greatly influenced by temperature, relative speed of the interacting surfaces [7], the normal load [8], and the environment [9]. Therefore, to deal with these effects and for better control of the responses, polymers are modified by adding appropriate fillers to suit the particular application. Thus, they are invariably used as a composite or in a blended form for optimum friction and wear performance [10].

Over the last decade, epoxy composites have seen increased use as structural materials in boating, automotive, and various other industries due to their lower weight compared to traditional materials like metals and ceramics [11]. Among these applications, many are related to the tribological components, where the self-lubrication properties of epoxy-based composites are very important [12]. The characteristic that makes epoxy composites promising in many applications is the possibility to control their properties by adding special fillers with different volume fractions, shapes, and sizes [13,14]. The integration of well-dispersed carbon particles into an epoxy

* Corresponding author: M. M. SAKKA, E-mail: sakkamedmahdi@yahoo.fr 
matrix has been demonstrated to be quite effective at improving the performance of epoxy composites, including their tribological properties [15]. It has been found that nano- and micro-sized carbon particles can be used to modify the tribological properties of polymeric materials [16]. Friedrich and Schlarb have demonstrated that these fillers could considerably improve the wear and friction properties of both coatings and bulk materials by strengthening the matrix (high load-carrying capacity), improving the sub-surface crack arresting ability (better toughness), and improving the lubricating effect at the interface by decreasing shear stress [6]. Among all fillers, graphite is widely used as an efficient solid lubricant to enhance the tribological properties of polymer composites due to the weak Van der Waals bonds between the graphite layer structures. In fact, under sliding conditions, the shear force can easily break the graphite structure. Graphite flakes are symmetrically distributed on the sliding surface, which reduces the direct contact between the composites and steel counterparts [17]. Zhang et al. [18] confirmed that the wear rate and the friction coefficient of polyphtalazinone ether sulfone ketone (PPESK) composites decreased with the increase of the graphite volume fraction. Chang et al. [19] found that the specific wear rate of polyetherimide (PEI) filled with graphite was 800 times lower than that of a neat matrix under standard testing conditions.

Shalwan et al. studied the influence of date palm fiber and graphite filler on mechanical and wear characteristics of epoxy composites. They concluded that the addition of graphite allows the enhancement of wear resistance over the natural fiber/polymer composites. However, the authors also found that a high graphite ratio deteriorates the mechanical properties [20].

Apart from graphite, other fillers can be used to enhance the tribological properties, especially nanoscale fillers. It has been found that particle size has great influence on the tribological performance of polymer composites [21]. When the particle size is reduced down to the nanoscale, the friction and wear behavior of filled polymers is greatly affected at very low nanoparticle content as compared to the effect of low micro-filler content on friction and wear behavior of the filled polymers [22]. But the influence on friction and wear behavior of nanoparticles in polymer matrices depends on many factors such as the type of polymer, type of nanoparticle, filler content, size, shape, and operating conditions [6].

Multiwalled carbon nanotubes (MWCNTs) are a class of nanomaterials that have a diameter of a few dozens of $\mathrm{nm}$ and a length of some $\mathrm{mm}$. Thanks to this high-aspect ratio, carbon nanotubes (CNTs) can provide special mechanical properties, which are experimentally demonstrated by different researchers [23-26]. Several research efforts on the effect of CNTs on the tribological properties of polymers have been published. Gong et al. compared the tribological properties of carbon fiber composites with CNT composites. They proved that composites with CNTs as reinforcing elements exhibit more stable frictional coefficients and lower wear rates, especially at high temperatures due to their perfect graphite layered structure [27]. Chen et al. report that CNTs can clearly decrease the friction coefficient and the wear rate of copper and polytetrafluoroethylene (PTFE) based composites [28, 29]. Lim et al. [30] studied carbon/ carbon composites coated with CNT reinforced carbon, and they found that the wear rate decreased with increasing CNT volume fraction. In the case of PTFE based composites, the friction coefficient decreased continuously with increasing CNT content up to $30 \mathrm{vol} \%$. Zoo et al. studied the effect of MWCNT addition on the tribological behavior of ultra high molecular weight polyethylene (UHMWPE) [31]. In contrast to the previous findings for PTFE, they found that the friction coefficient increases continuously when CNTs are added up to $0.5 \mathrm{wt} \%$. These results were explained by the poor dispersion of MWCNTs in the composite, which has a direct impact on the composite tribological and mechanical properties.

To solve this dispersion problem, many solutions [32-34] have been suggested, like the addition of dispersing agents [35], shear mixing [36], and functionalization [37]. The last solution is one of the most efficient methods, which improves compatibility between CNTs and the polymer matrix. For example, by adding 0.1 to $1 \mathrm{wt} \%$ MWCNTs grafted with epoxy, Jia et al. [38] observed a $45 \%$ increase in tensile strength and $90 \%$ improvement in tensile modulus. Sun et al. [39] successfully grafted PAMAM-0 on thesurfaces 
of the single walled carbon nanotubes(SWCNTs), which induced an enhanced dispersion and adhesion state of CNTs in epoxy resin.

Cha et al. have tried to improve the dispersion of carbon nanotubes (CNTs) in epoxy matrix composites by attaching polystyrene sulfonate (PSS) and poly(4aminostyrene) (PAS) on the surface of CNTs by noncovalent functionalization; they found that this incorporation of noncovalently functionalized CNTs into the modified bisphenol-A type epoxy matrix yielded a Young's modulus of $3.89 \mathrm{GPa}$ and a tensile strength of $82.59 \mathrm{MPa}$, with the addition of $1 \mathrm{wt} . \%$ PAS-CNTs. These results were explained by the better dispersion of CNTs in the matrix and the chemical bonding generated between the amino groups and the epoxide groups in the epoxy matrix [40].

The fundamental and detailed understanding of the influence of nanoparticles on tribological properties of filled polymers remains an open field for further research. Several studies have been conducted on the tribological properties of carbon/epoxy composites, but few have focused on the correlation between the friction coefficient and generated heat. Unfortunately, few authors have given much attention to the synergetic effect of two incorporated fillers on epoxy matrix. In the present study, graphite and/or CNTs were incorporated into an epoxy matrix. The purpose of our work is to investigate the synergistic effect of the two fillers on the tribological behavior of epoxy-carbon filler composites. Scanning electron microscopy (SEM) observations were used to determine the wear mechanisms of the implemented composite. Finally, special importance is attributed to thermal phenomena related to the coefficient of friction.

\section{Experimental details}

\subsection{Materials}

The epoxy resin used in this study, Epolam 2020, was purchased from Axon Technologies. It was designed for the production of composite structures by the usual wet lay-up methods, vacuum infusion, low-pressure injection, or filament winding. Carbon nanotubes master batches, 3150 and 3152, were provided by NANOCYL (Belgium). The main difference between the two grades is the use of functionalized CNTs for the 3152 grade, where $\mathrm{NH}_{2}$ groups are grafted to CNTs via a NANOCYL patented process. CNTs are produced via the catalytic carbon vapor deposition (CCVD) process. The average diameter of the CNTs was $9.5 \mathrm{~nm}$, and the average length was about $1 \mu \mathrm{m}$. Graphite TIMREX BNB 90 was provided by TIMCAL (Switzerland). Expanded graphite foil size varied between $10 \mu \mathrm{m}$ and $85 \mu \mathrm{m}$.

\subsection{Sample preparation}

Five different types of samples were prepared as mentioned in Table 1. In each of the non-neat samples, a $1.5 \%$ weight fraction of either CNTs, $\mathrm{NH}_{2}-\mathrm{CNTs}$ (TCNTs), graphite or CNTs/graphite were introduced. The ratio used for the mixture of CNT and graphite was $1 / 3$ to $2 / 3$, respectively. A reference sample was prepared from neat epoxy. Samples were prepared by mixing the epoxy resin with $34 \mathrm{wt} \%$. of hardener. Subsequently, the mixture was flowed into a mold of $2 \mathrm{~mm}$ thickness.

The reticulation process was conducted by drying the mixture for 24 hours at room temperature. The post curing cycle (Fig. 1), uses a temperature ramp of $20^{\circ} \mathrm{C} / \mathrm{h}$. The epoxy was held at $40{ }^{\circ} \mathrm{C}$ for 3 hours,

Table 1 Designation and composition of the different prepared samples.

\begin{tabular}{cc}
\hline Specimens & Composition \\
\hline Ep & Neat epoxy \\
Ep-Gr & Epoxy $+1.5 \mathrm{wt} \%$ graphite \\
Ep-CNTs & Epoxy $+1.5 \mathrm{wt} \%$ CNTs \\
Ep-TCNTs & Epoxy $+1.5 \mathrm{wt} \%$ TCNTs \\
Ep-HYB & Epoxy $+1.5 \mathrm{wt} \%(1 / 3 \mathrm{CNTs}+2 / 3$ graphite $)$ \\
\hline
\end{tabular}

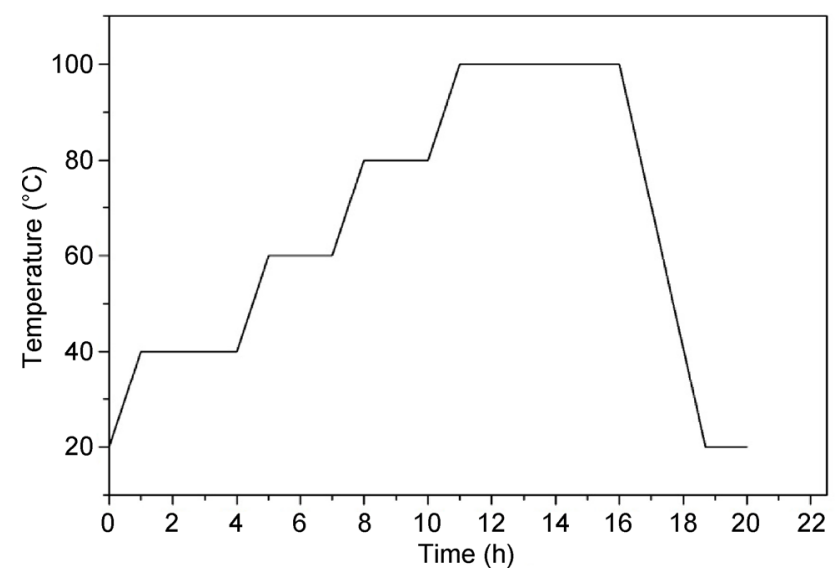

Fig. 1 Postcuring cycle of epoxy samples. 
at $60{ }^{\circ} \mathrm{C}$ for 2 hours, at $80{ }^{\circ} \mathrm{C}$ for 2 hours, and then at $100{ }^{\circ} \mathrm{C}$ for 5 hours. The cooling rate was $30^{\circ} \mathrm{C}$ /hour. The obtained plates were cut by milling to get square samples of $20 \mathrm{~mm}$ on a side. All samples were polished using abrasive papers (from 400 to 1000 grades) and diamond paste.

\subsection{Friction and wear test}

Friction and wear tests were conducted using a rotating pin-on-disc tribometer under dry sliding conditions. This tribometer is shown in Fig. 2. The friction test was performed using a $6 \mathrm{~mm}$ diameter 100Cr6 ball bearing, and the radius of the wear track is $5 \mathrm{~mm}$. The different values of normal load and velocity are illustrated in the legend of Fig. 3. The steel ball was kept stationary and a continuous rotating motion was applied to the composite specimen. The maximum contact pressure, calculated with Hertz theory, was $130 \mathrm{MPa}$. Tests were performed at $25^{\circ} \mathrm{C}$ and a relative humidity of $60 \%$. The sliding test duration was about $64 \mathrm{~min}$. At least three tests were performed for each set of conditions. The average contact temperature was measured during the test using a thermocouple connected to the steel ball that was $2 \mathrm{~mm}$ from the contact point and located at the edge of the ball. Weight loss values were determined by using a balance of $10^{-4} \mathrm{~g}$ of precision.

The wear rate was calculated by measuring weight loss of each sample $\Delta m$ after wear testing, divided by the applied load $F_{\mathrm{n}}$ and the sliding distance $S$. The corresponding density was given by $\rho$. The cumulative wear rate $W_{\mathrm{r}}$ can be determined by the following equation:

$$
W_{\mathrm{r}}=\frac{\Delta m}{F_{\mathrm{n}} \cdot \rho \cdot S}
$$

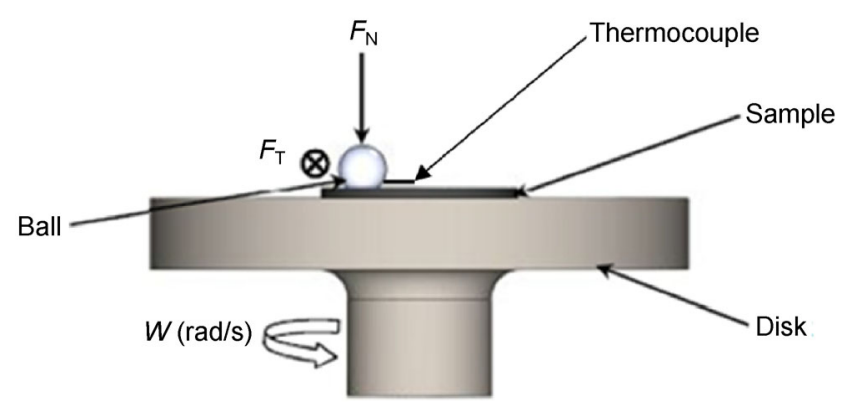

Fig. 2 Pin-on-disc tribometer.
The main variables that affect wear are sliding velocity and normal load. In addition, the materials' structure, properties, and the environmental conditions affect the wear rate.

\subsection{Scanning electron microscopy}

After the wear test, wear tracks were observed (after metal coating) with a JEOLJSM-6031F scanning electronic microscope, using a conventional tungsten cathode at $12 \mathrm{kV}$ accelerating voltage in secondary electron image mode.

\section{Results and discussion}

\subsection{Friction coefficient}

The friction coefficients of the prepared samples are presented as a function of time in Fig. 3. We notice that, at first, the friction coefficients can be significantly less when fillers are incorporated into the epoxy matrix. The highest friction coefficient value of 0.65 , and the lowest, of 0.1 , were obtained with neat epoxy and treated carbon nanotube filled composites, respectively.

Moreover, we could easily distinguish the existence of two different types of response curves; it is clear that Ep and Ep-TCNT samples behave differently from other samples. In the case of the Ep-TCNT composite, treated carbon nanotubes are well dispersed on the epoxy due to the presence of $\mathrm{NH}_{2}$ groups. As a result, generated debris, which are probably rich in $\mathrm{NH}_{2}-\mathrm{CNT}$, will change the friction contact properties by the creation of a low-friction tribo-layer. The transfer film, obtained during sliding, could act as a lubricant, which would lead to a significant decrease of the friction coefficient [41].

In the case of the Ep samples brought into contact with the 100Cr6 steel ball, we assume that a transfer film was formed on the ball and stuck to it, via tribochemical interactions with the counter body material [42]. When this layer is present on both contacting surfaces, the composition of the sample and the sliding counter body becomes similar and then the coefficient of friction becomes stable [43].

For the second type of curves (Ep-CNT, Ep-Gr, and Ep-HYB in Fig. 3), three stages can be observed. The first stage, which corresponds to a run-in-period, is characterized by a stable friction coefficient of $0.1,0.1$, 

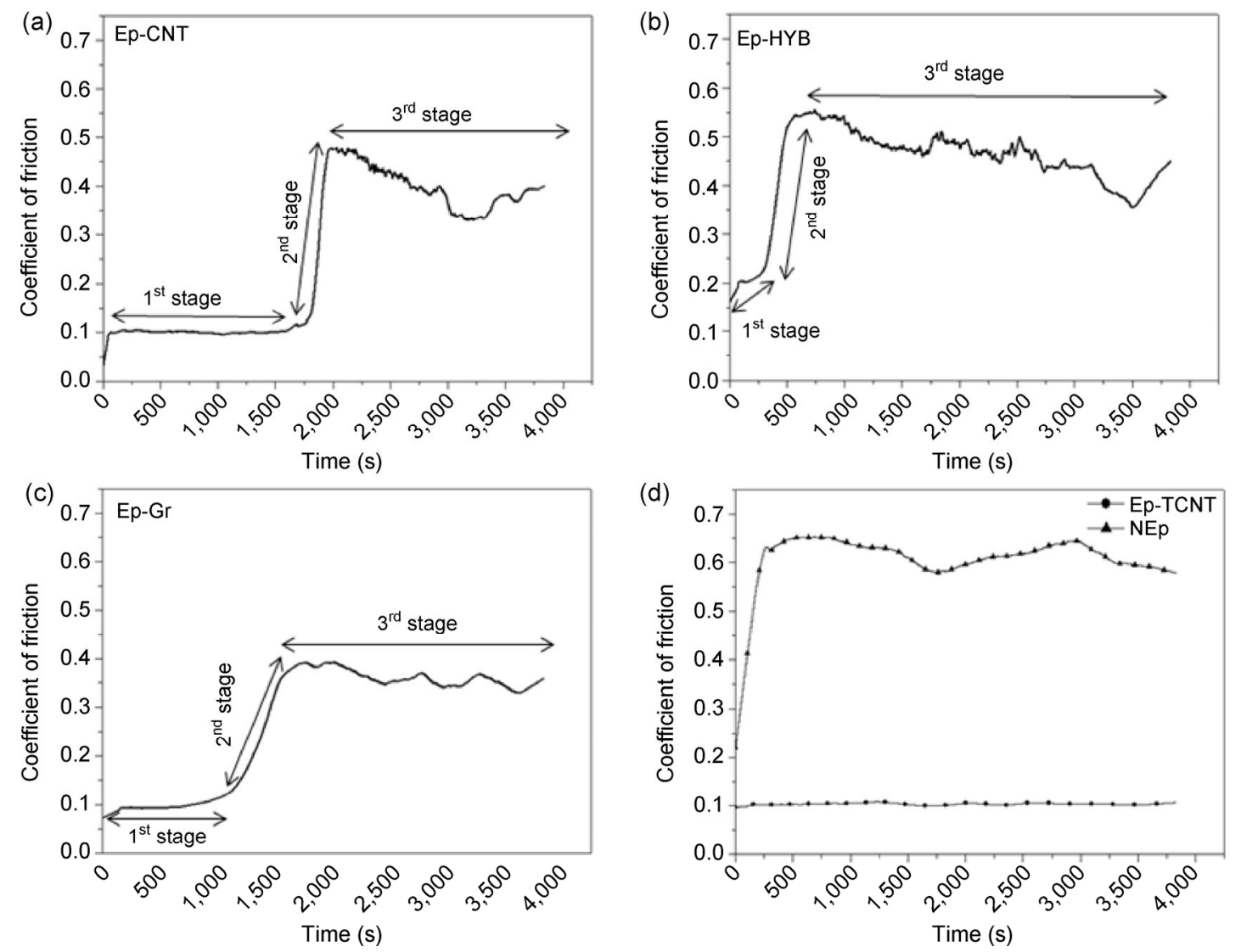

Fig. 3 Coefficient of friction evolution for the different types of samples at $400 \mathrm{rpm}$ and $F_{\mathrm{n}}=4 \mathrm{~N}$.

and 0.2 for the Ep-CNT, Ep-Gr, and Ep-HYB, respectively. The duration of this stage is about $1,750 \mathrm{~s}$, $1,200 \mathrm{~s}$, and $250 \mathrm{~s}$ for each of those. Consequently, it can be concluded that CNTs have the best adhesion to the epoxy matrix, since it takes more time for them to be extracted. In fact, CNTs have higher specific surfaces than graphite, which explains their better adhesion to epoxy. The second stage was characterized by a significant increase of friction coefficient from 0.1 to $0.47,0.1$ to 0.4 , and 0.2 to 0.55 for Ep-CNT, Ep-GR, and Ep-HYB, respectively. The increase of friction coefficients could be explained as follows. Firstly, debris was created, which then accumulated on the sliding track, and finally adhered to the steel ball. At this moment, the contact was no longer between $100 \mathrm{Cr} 6$ and the sample but, instead, switched to sample-sample contact. In the third stage, the sliding rotating motion intermittently ejects a fraction of the created debris out of the wear track circumference, which explains the fluctuations of the friction coefficient curves.

\subsection{Correlation between friction coefficients and temperature}

A strong correlation between friction coefficient and temperature is observed in the samples (Fig. 4). Specifically, the temperature considerably increases when debris are initially created (stage II) at the interface. The wear track roughness increases and local heating begins. In fact, on the microscopic scale, the flash temperature occurs at the contact asperities over a very short duration, lower than a millisecond. These local, but microscopic, flash temperature fluctuations are, actually, hundreds of times higher than the average contact temperature [44]. The accumulation of these flash temperature events could be responsible for the rise of the average temperature measured by the thermocouple. It is also observed that a higher velocity of rotation leads to a higher temperature (Fig. 5). This result is explained by the increase of sliding distance, which creates more heat.

Figure 5 shows the presence of brown zones, which 

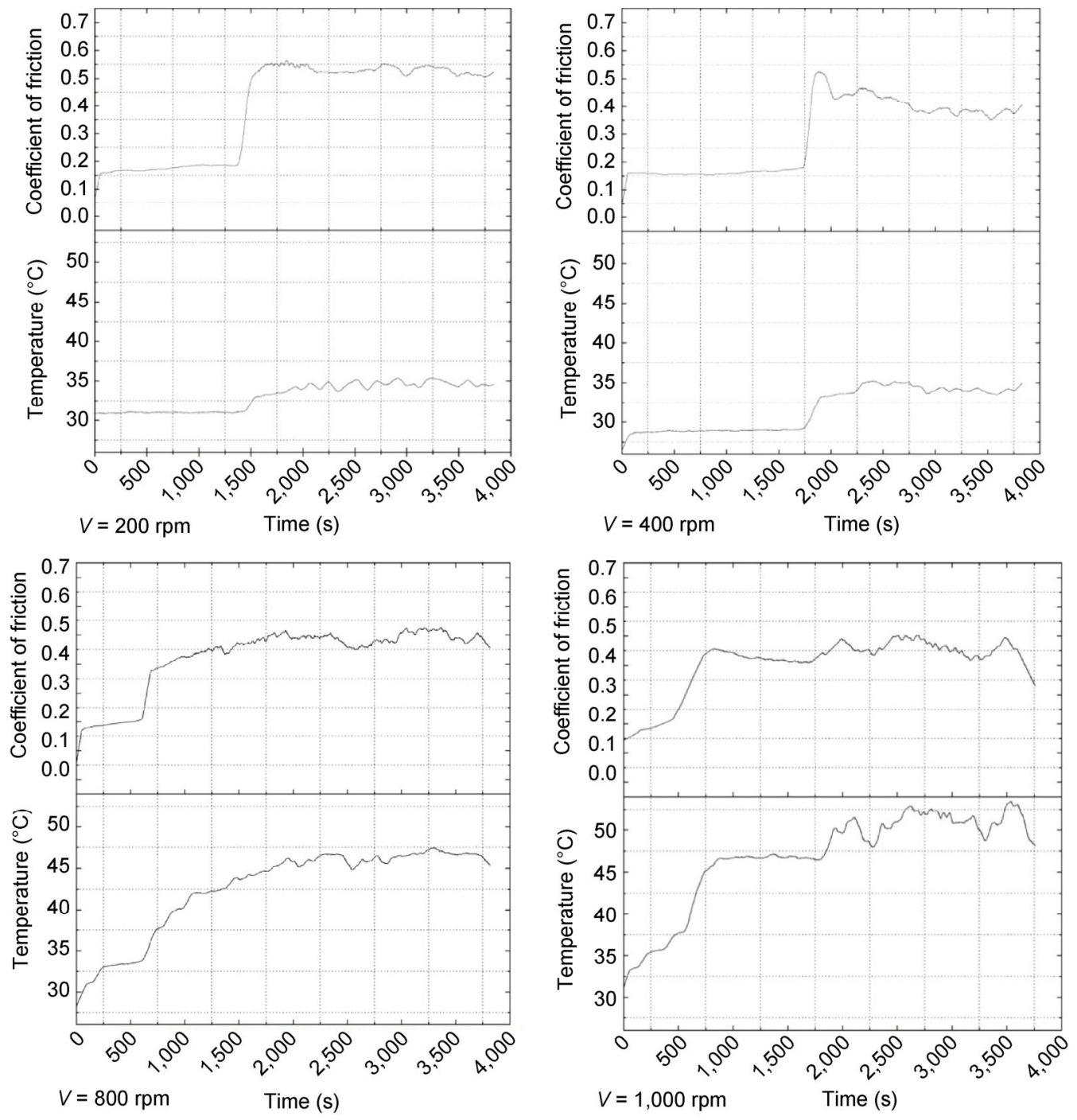

Fig. 4 Correlation between the coefficient of friction and temperature for the Ep-CNT samples at $F_{\mathrm{n}}=8 \mathrm{~N}$ and different velocities.

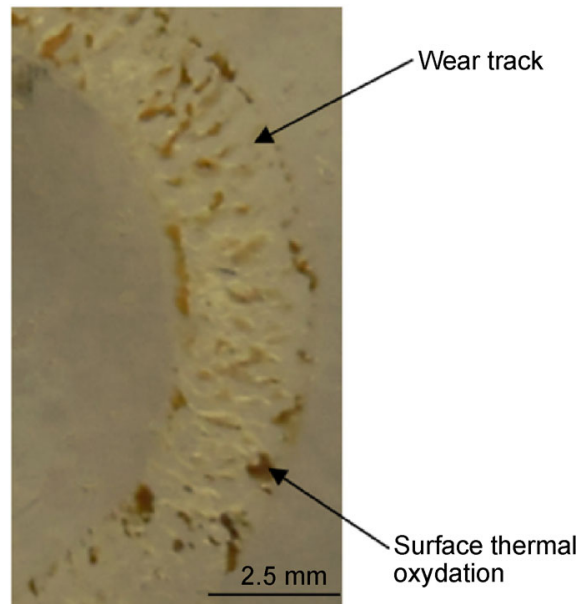

Fig. 5 Surface color modification after dry sliding test of Ep sample at $F_{\mathrm{n}}=8 \mathrm{~N}$ and $V=1,000 \mathrm{rpm}$. are a thermal modification of the wear track surface. In fact, the color of the tested surface shifts from yellowish to brown after the sliding test. Similar results were also reported by Hancox [45] and Greer et al [46], and they explain the color change by a chemical modification of the resin surface. More precisely, it was thought that color change is essentially the result of thermal oxidation caused by the flash temperature [47].

\subsection{Wear loss and wear mechanism}

Figure 6 shows the effect of the incorporation of TCNTs, CNTs, GR, and HYB fillers on the wear rate of the epoxy resin. It is clearly shown that filler 


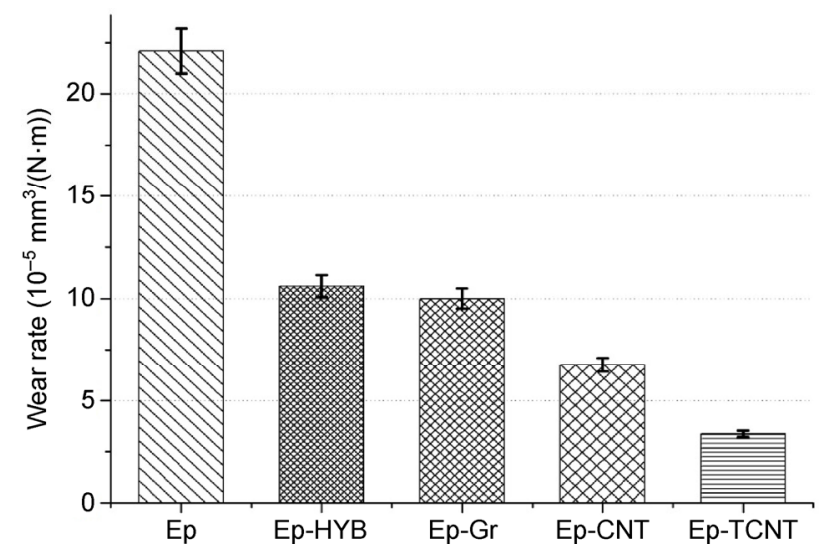

Fig. 6 Wear rate of different types of samples.

addition, to the neat epoxy, can decrease significantly the wear rate. It was found that the least wear rate was obtained when $1.5 \mathrm{wt} \%$ TCNTs was added to the epoxy matrix; in fact, the wear rate of Ep decreases from $22.1 \times 10^{-5} \mathrm{~mm}^{3} \cdot \mathrm{N}^{-1} \cdot \mathrm{m}^{-1}$ to $3.37 \times 10^{-5} \mathrm{~mm}^{3} \cdot \mathrm{N}^{-1} \cdot \mathrm{m}^{-1}$. Moreover, similar behavior was observed for the other composites. Samples could be classified according to their wear rate, from the highest to the lowest, as follow: Ep, Ep-HYB, Ep-GR, Ep-CNTs, and Ep-TCNTs. These results may be explained by the difference of adhesion quality between fillers and the epoxy matrix $[48,49]$. CNTs have a better adhesion due to their high aspect ratio. However, graphite pieces are easily extracted as they have a layered planar structure $[50,51]$. The functionalization of CNTs with amine groups enhances the interaction between CNTs and the epoxy matrix [52], which improves the mechanical properties and the wear resistance of the obtained composite.

The SEM images of the worn surfaces, presented in Fig. 7, give some information about the wear mechanism. The lack of grooves on the wear track indicates that an abrasive mechanism does not contribute to the wear for all composites. The worn surfaces (Figs. 7(a)-7(d)) are rough and present delamination marks suggesting an adhesive wear mechanism. This result is due to the poor wear resistance of the Ep [53] and the poor adhesion of fillers to the epoxy matrix. Moreover, it seems that wear debris are crushed and spread on the wear track surface.

Figure 8 shows a thin film adherent to the steel ball after testing. Thus, wear progress of the composite can be described by three different stages [54]. First, adhesive processes cause the resin transfer to the ball surface and a progressive rise of the real contact surface. At the same time, in the sub-surface of the epoxy resin, progressive damage is taking place that is caused by the propagation of sub-surface cracks. When these cracks emerge on the surface, the final phase occurs, which is characterized by mechanical and thermal fatigue wear [54].

However, Ep-TCNTs composites have a different behavior, as they were characterized by a smooth worn surface and the absence of delamination marks (Fig. 7(e)). It can be concluded that the adhesion on the worn surface of Ep-TCNT composites is reduced. Thus, it seems that the improved adhesion of CNTs can considerably decrease the adhesion mechanism. As a result, the Ep-TCNTs composites show better wear resistance than the neat epoxy.

According to Chen et al. [54-56] and Cai et al. [57], wear of Ep-TCNT nano-composites, in dry sliding against a carbon steel ball, may be controlled by two factors. The incorporation of CNTs in Ep helps to ameliorate the mechanical properties of the nanocomposites (Table 2), which leads to an enhancement of the wear resistance [50].

Moreover, the well dispersed TCNTs (Fig. 9) are removed from the nano-composites and transferred to the interface between the nano-composites and the steel ball. Hence, CNTs may play the role of spacers preventing close contact between the steel ball and the nano-composites. In fact, CNTs will be shortened first and then flatten to form a graphene-like lamella, which decreases the wear loss and causes the decrease of the friction coefficient [51] (Fig. 10).

\section{Conclusions}

The study of the effects of carbon fillers on the tribological behavior of an Epolam 2020 epoxy resin sliding against a $100 \mathrm{Cr} 6$ steel ball revealed some interesting points in relation to the wear and friction of this material.

- Two tribological behaviors are observed: the first is characterized by a constant friction coefficient (Ep and Ep-TCNTs) and the second by the detection of three friction stages. 

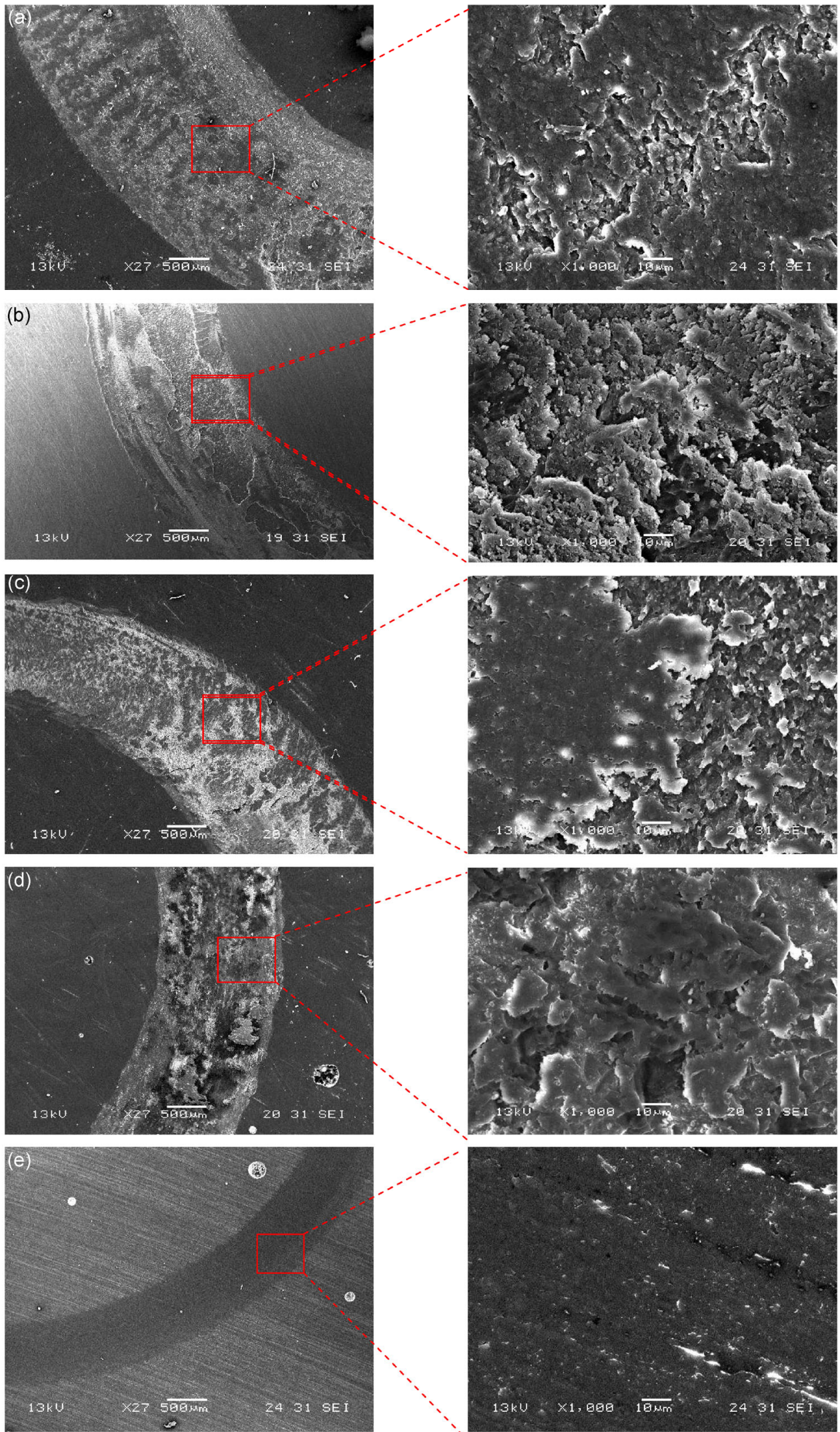

Fig. 7 SEM observation of worn surfaces for the different types of samples: (a) Ep, (b) Ep-Gr, (c) Ep-CNT, (d) Ep-HYB, and (e) Ep-TCNT. 

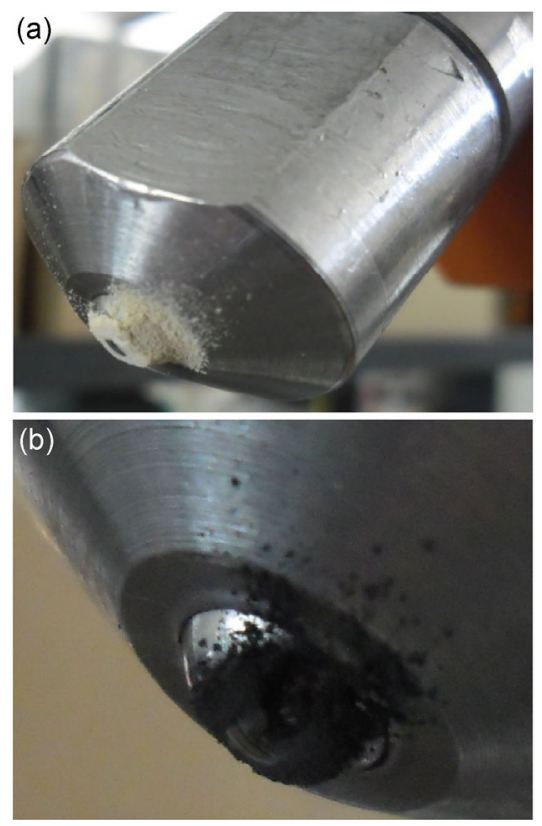

Fig. 8 Transfer film adherent to the steel ball: (a) Ep and (b) Ep-Gr.

Table 2 Young's modulus of the different tested specimens.

\begin{tabular}{cc}
\hline Specimens & Young modulus $(\mathrm{GPa})$ \\
\hline Ep & 2.6 \\
Ep-Gr & 2.9 \\
Ep-CNTs & 3.3 \\
Ep-TCNTs & 3.8 \\
Ep-HYB & 2.7 \\
\hline
\end{tabular}
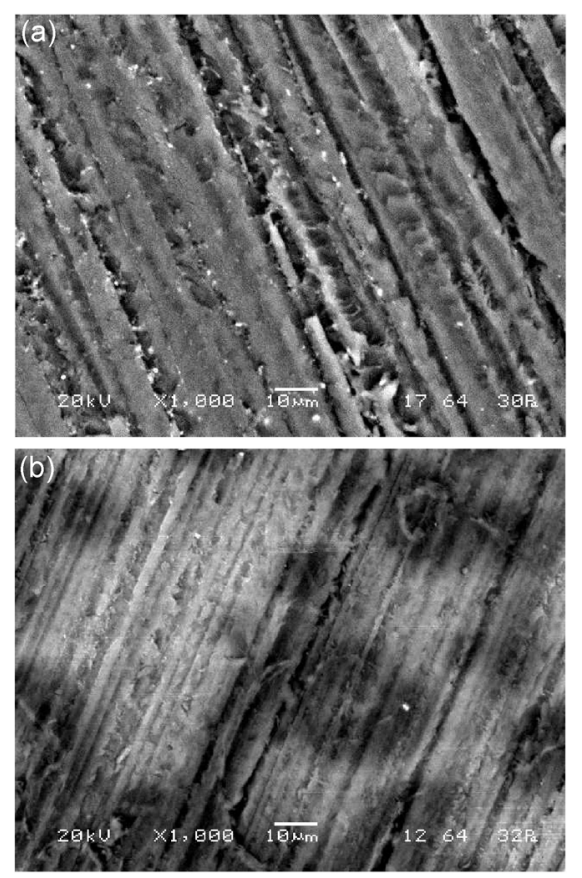

Fig. 9 SEM images showing the dispersion of (a) TCNT and (b) CNT in an epoxy matrix. (a)
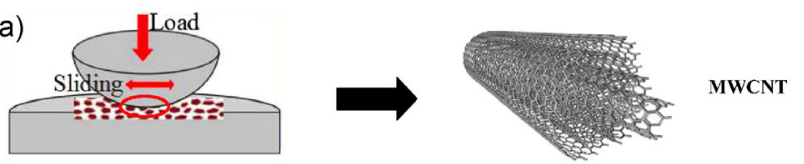

(b)
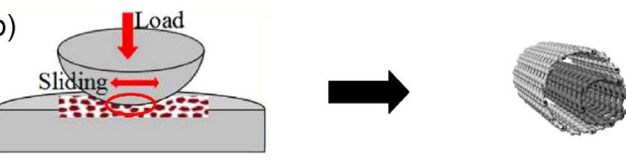

Shorten

(c)
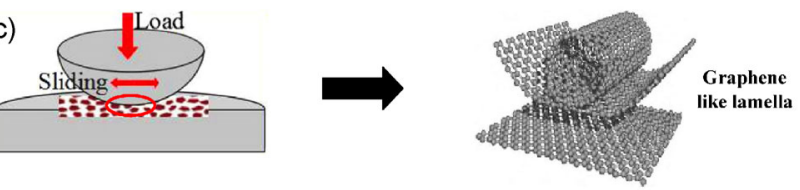

(d)
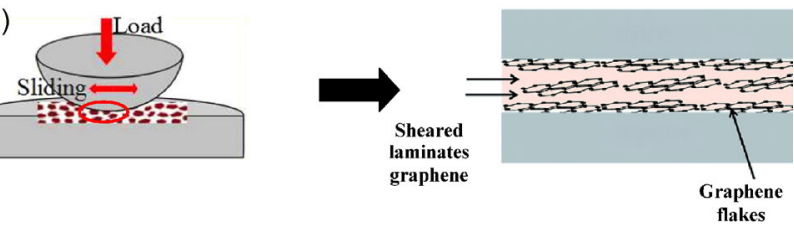

Fig. 10 Schematic diagram showing the effect of carbon additives on the wear resistance of epoxy matrix: (a) stage 1, (b) stage 2, (c) stage 3 , and (d) stage 4 .

- Wear resistance is enhanced by the incorporation of carbon fillers in the epoxy matrix. The best result is obtained with TCNTs, which are well dispersed in the epoxy matrix due to the presence of the $\mathrm{NH}_{2}$ groups.

- A correlation between friction coefficient and the measured average contact temperature is found. The rise of this temperature could be explained by the accumulation of flash temperature events, which are higher than the average contact temperature.

- The predominant wear mechanism is adhesive wear, which leads to both crack emergence on the surface and delamination. This mechanism is encountered in all composites, except Ep-TCNT composites.

- Despite the enhanced wear resistance of both EpCNTs and Ep-Gr, Ep-HYB has the inferior tribological properties of the three. Consequently, there is no synergetic effect between graphite and CNTs.

\section{Acknowledgements}

This work was supported by the national school of engineers of Sfax, Tunisia represented by the Laboratory of material engineering and environment (LGME) and the University of South Brittany, Lorient, France, and represented by the laboratory of material engineering of Brittany (LimatB), smart plastic group. 
Open Access: The articles published in this journal are distributed under the terms of the Creative Commons Attribution 4.0 International License (http:// creativecommons.org/licenses/by/4.0/), which permits unrestricted use, distribution, and reproduction in any medium, provided you give appropriate credit to the original author(s) and the source, provide a link to the Creative Commons license, and indicate if changes were made.

\section{References}

[1] Briscoe B J, Sinha S K. Tribology of polymeric solids and their composites. In Wear-Materials, Mechanism and Practice, 2005: 223-267.

[2] Yousef S. Polymer nanocomposite components: A case study on gears. In Light Weight Composite Structures in Transport Design, Manufacturing, Analysis and Performance. 2016: 385-420.

[3] Koike H, Kida K, Santos E C, Rozwadowska J, Kashima Y, Kanemasu K. Self-lubrication of PEEK polymer bearings in rolling contact fatigue under radial loads. Tribol Int 49: 30-38 (2012)

[4] Juvonen T, Selenius M. Joint bearing surfaces and replacement joint design. In Joint Replacement Technology (Second Edition). Finland, 2014: 167-185.

[5] Joshi M, Chatterjee U. Polymer nano-composite: An advanced material for aerospace applications. In Advanced Composite Materials for Aerospace Engineering, Processing, Properties and Applications. New Delhi, 2016: 241-264.

[6] Friedrich K, Schlarb A. Tribology of polymeric nanocomposites. In Tribology and Interface Engineering Series, No. 55. Series Editor. Briscoe B J, 2008.

[7] Cho D-H, Bhushan B. Friction and wear of various polymer pairs used for label and wiper in labeling machine. Tribol Int 98: 10-19 (2016)

[8] Larsen J, Hinge M. Temperature- and time dependency on high friction poly(styrene-co-butyl methacrylate) coated paper Christoffer Bjerremand. Tribol Int 103: 261-265 (2016)

[9] Laux K A, Jean-Fulcrand A, Sue H J, Bremner T, Wong J S S. The influence of surface properties on sliding contact temperature and friction for polyetheretherketone (PEEK). Polymeric Materials and Characterization Methods for Water Purification 103: 397-404 (2016)

[10] Friedrich K, Pei X Q. Friction and wear of polymer composites. Reference Module in Materials Science and Materials Engineering (2016)
[11] Jin F-L, Li X. Synthesis and application of epoxy resins: A review. J Ind Eng Chem 29(25): 1-11 (2015)

[12] Kumar V, Sinha S K, Agarwal A K. Tribological studies of epoxy composites with solid and liquid fillers. Tribol Int 105: 27-36 (2017)

[13] Katiyar J K, Sinha S K, Kumar A. Friction and wear durability study of epoxy-based polymer (SU-8) composite coatings with talc and graphite as fillers. Wear 362-363: 199-208 (2016)

[14] Zhang L, Zhang G, Chang L, Wetzel B, Jim B, Wang Q. Distinct tribological mechanisms of silica nano-particles in epoxy composites reinforced with carbon nanotubes, Tribol Int 104: 225-236 (2016)

[15] Zhang G, Sebastian R, Burkhart T, Friedrich K. Role of monodispersed nanoparticles on the tribological behavior of conventional epoxy composites filled with carbon fibers and graphite lubricants. Wear 292-293: 176-187 (2012)

[16] Zhang M Q, Rong M Z, Yu S L, Wetzel B, Friedrich K. Effect of particle surface treatment on the tribological performance of epoxy based nano-composites. Wear 253: 1086-1093 (2002)

[17] Suresha B, Chandramohan G, Renukappa M N, Siddaramaiah. Mechanical and tribological properties of glass-epoxy composites with and without graphite. J Appl Polym Sci 103: 2472-2480 (2007)

[18] Zhang X, Liao G, Jin Q, Feng X, Jian X. On dry sliding friction and wear behavior of PPESK filled with PTFE and graphite. Tribol Int 41: 195-201 (2008)

[19] Chang L, Zhang Z, Zhang H, Friedrich K. Effect of nanoparticles on the tribological behavior of short carbon fibre reinforced poly(etherimide) composites. Tribol Int 38: 966-973 (2005)

[20] Shalwan A, Yousif B F. Influence of date palm fibre and graphite filler on mechanical and wear characteristics of epoxy composites. Materials and Design 59: 264-273 (2014)

[21] Lin J-C. Compression and wear behavior of composites filled with various nano-particles. Composites. Part B-Engineering 38: 79-85 (2007)

[22] Chauhan S R, Thakur S. Effects of particle size, particle loading and sliding distance on the friction and wear properties of chemosphere particulate filled vinyl ester composites. Materials \& Design 51: 398-408 (2013)

[23] Meyyappan M. Carbon Nanotubes: Science and Applications. Taylor \& francis Group, CRC Press, 2005.

[24] Ruoff R S, Lorents D C. Mechanical and thermal properties of carbon nanotubes. Carbon 33: 925-930 (1995)

[25] Gojny F H, Schulte K. Functionalisation effect on the thermomaechanical behiviour of multi-wall carbon nanotube/epoxy 
composite. Composite Science Technology 64: 2303-2308 (2004)

[26] Allaoui A, Bai S, Cheng H M, Cheng J B. Mechanical and electrical properties of a MWNT/epoxy composite. Composite Science Technology 62: 1993-1998 (2002)

[27] Gong Q, Li D, Li Z, Yi X, Liang J. Chapter $10-$ Tribological properties of carbon nanotube-reinforced composites. In Tribology of Polymeric Nanocomposites (Second Edition), Friction and Wear of Bulk Materials and Coatings, 2013: 353-386.

[28] Chen W X, Li F, Han G, Xia J B, Wang L Y, Tu J P, Xu Z D. Tribological behavior of carbon-nanotube-filled PTFE composites. Tribol Lett 15: 275-278 (2003)

[29] Chen W X, Tu J P, Wang L Y, Gan H Y, Xu Z D, Zhang $\mathrm{X}$ B. Tribological application of carbon nanotubes in a metal-based composite coating and composites. Carbon 41: 215-222 (2003)

[30] Lim D-S, An J-W, Lee H J. Effect of carbon nanotube addition on the tribological behavior of carbon/carbon composites. Wear 252: 512-517 (2002)

[31] Zoo Y-S, An J-W, Lim D-P, Lim D-S. Effect of carbon nanotube addition on tribological behavior of UHMWPE. Tribol Lett 16: 305-309 (2004)

[32] Khare B N, Wilhite P, Quinn R C, Chen B, Schingler R H, Tran B, Imanaka H, So C R, Bauschlicher W, Meyyappan M. Functionalization of carbon nanotubes by ammonia glow-discharge: Experiments and modeling. J Phys Chem 108: 8166-8172 (2004)

[33] Felten A, Bittencourt C, Pireaux J J, Lier G V, Charlier J C. Radio-frequency plasma functionalization of carbon nanotubes surface $\mathrm{O}_{2}, \mathrm{NH}_{3}$, and $\mathrm{CF}_{4}$ treatments. $J$ Appl Phys 98: 074308 (2005)

[34] Rodríguez M A, Gil L, Camero S, Fréty N, Santana Y, Caro J. Effects of the dispersion time on the microstructure and wear resistance of $\mathrm{WC} / \mathrm{Co}-\mathrm{CNT}$ HVOF sprayed coatings. Surface Coat Technol 258: 38-48 (2014)

[35] Kim M T, Rhee K Y, Lee J H, Hui D, Lau A K T. Property enhancement of a carbon fiber/epoxy composite by using carbon nanotubes. Composites: Part B 42: 1257-1261 (2011)

[36] Jacobs O, Xu W, Schadel B, Wu W. Wear behaviour of carbon nanotube reinforced epoxy resin composites. Tribol Lett 23: 65-75 (2006)

[37] Yang K, Gu M, Guo Y, Pan X, Mu G. Effects of carbon nanotube functionalization on the mechanical and thermal properties of epoxy composites. Carbon 47: 1723-1737 (2009)

[38] Jia J, Chen J, Zhou H, Hu L, Chen L. Comparative investigation on the wear and transfer behaviors of carbon fiber reinforced polymer composites under dry sliding and water lubrication. Compos Sci Technol 65: 1139-1147 (2005)

[39] Sun L, Warren G L, O’Reilly J Y, Everett W N, Lee S M, Davis D, Lagoudas D, Sue H-J. Mechanical properties of surface-functionalized SWCNT/epoxy composites. Carbon 46: 320-328 (2008)

[40] Cha J, Jin S, Shim J H, Park C S, Ryu H J. Functionalization of carbon nanotubes for fabrication of CNT/epoxy nanocomposites. Materials \& Design 95: 1-8 (2016)

[41] Lu X, Wong K C, Wong P C, Mitchell K A R, Cotter J, Eadie D T. Surface characterization of polytetrafluoroethylene (PTFE) transfer films during rolling-sliding tribology tests using X-ray photoelectron spectroscopy. Wear 261(10): 1155-1162 (2006)

[42] Suresha B, Siddaramaiah, Kishore, Seetharamu S, Kumaran PS. Investigations on the influence of graphite filler on dry sliding wear and abrasive wear behavior of carbon fabric reinforced epoxy composites. Wear 14: 1405-1414 (2009)

[43] Davim J P, Cardoso R. Effect of the reinforcement (carbon or glass fibers) on friction and wear behaviour of the PEEK against steel surface at long dry sliding. Wear 266: 795-799 (2009)

[44] Zaidi H, Frene J. Tempertaure de l'interface des contacts glissant à sec. In 19ème congrès français de mécanique, Marseille, france, 2009.

[45] Hancox N L. Thermal effects on polymer matrix composites: Part 2. Thermal degradation. Materials \& Design 19: 93-97 (1998)

[46] Rose N, le Bras M, Bourbigot S, Delobel R. Thermal oxidative degradation of epoxy resins: evaluation of their heat resistance using invariant kinetic parameters. Polymer Degradation and Stability 45: 387-397 (1994)

[47] Buch X, Shanahan M E R. Thermal and thermo-oxidative ageing of an epoxy adhesive. Polymer Degradation and Stability 68: 403-411 (2000)

[48] Suresha B, Ramesh B N, Subbaya K M, Ravi Kumar B N, Chand Ramohan G. Influence of graphite filler on two-body abrasive wear behaviour of carbon fabric reinforced epoxy composites. Materials and Design 31: 1833-1841 (2010)

[49] Gantayat S, Prusty G, Rout D R, Swain S K. Expanded graphite as a filler for epoxy matrix composites to improve their thermal. Mechanical and Electrical Properties 30: 432-437 (2015)

[50] Dong B, Yang Z, Huang Y, Li H-L. Study on tribological properties of multi-walled carbon nanotubes/epoxy resin nano-composites. Tribol Lett 20(3-4): 251-254 (2005)

[51] Jacobs $\mathrm{O}, \mathrm{Xu} \mathrm{W}$, Scha del B, Wu W. Wear behaviour of carbon nanotube reinforced epoxy resin composites. Tribol Lett 23: 65-75 (2006) 
[52] Luo Y, Zhao Y, Cai J, Duan Y, Du S. Effect of aminofunctionalization on the interfacial adhesion of multi-walled carbon nanotubes/epoxy nano-composites. Materials \& Design 33: 405-412 (2012)

[53] Dong B, Yang Z, Huang Y, Li H-L. Study on tribological properties of multi-walled carbon nanotubes/epoxy resin nano composites. Tribol Lett 20: 251-254 (2005)

[54] Chen W X, Tu J P, Wang L Y, Gan H Y, Xu Z D, Zhang $X$ B. Tribological application of carbon nanotubes in a metal-based composite coating and composites. Carbon 41 : 215-222 (2003)

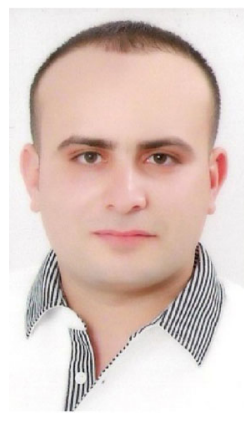

M. M. SAKKA. He received his engineer degree in materials engineering in 2010 from école nationale d'ingénieurs de Sfax, ENIS, Sfax University, Tunisia. In 2012, he had his master degree in materials and surfaces conducted in both University of Sfax, Tunisia and University of South Brittany, UBS, France.
[55] Chen W X, Li F, Han G, Xia J B, Wang L Y, Tu J P, Xu $\mathrm{Z}$ D. Tribological behavior of carbon nanotube-filled PTFE composites. Tribol Lett 15: 275-278 (2003)

[56] Chen W X, Tu J P, Xu Z D, Chen W L, Zhang X B, Cheng D H. Tribological properties of Ni-P-multi-walled carbon nanotubes electroless composite coating. Mater Lett 57: 1256-1260 (2003)

[57] Cai H, Yuan F Y, Xue Q J. Investigation of tribological properties of polyimide/carbon nanotube nano-composites. Mater Sci Eng 364: 94-100 (2004)

His current position is a Ph.D student in the laboratory of material engineering and environment, LGME in ENIS, Sfax, Tunisia. He had been a PhD visitor student between 2013 and 2016, in the frame work of the Marie-Curie research staff exchange scheme in Departement Materiaalkunde, MTM, KU Leuven, Belgium.

His research interests include polymers composite coating, thermal aspect of the contact, wear and friction of polymers. 